\title{
Synthesis and Characterization of A Novel Layered Aluminophosphate of Kanemite-like Structure
}

\author{
Soofin Cheng,* J eng-Ning Tzeng, and Bo-Ya Hsu \\ Department of Chemistry, National Taiwan University, Taipe, Taiwan 106, R.O.C. \\ Received J anuary 13, 1997. Revised Manuscript Received J une 2, $1997^{\otimes}$
}

\begin{abstract}
The synthesis and structural characterization of a novel layered aluminophosphate (named AIPO-ntu) with a structure mimicking to that of the naturally occurring silicate mineral kanemite are described. This new compound was synthesized using the hydrothermal method and n-alkylamines as templates. On the basis of the results of thermal and elemental analysis, the chemical formulas were determined to be $\operatorname{AIPO}(\mathrm{OH})_{2}\left[\mathrm{NH}_{2}\left(\mathrm{CH}_{2}\right)_{x} \mathrm{CH}_{3}\right](\mathrm{x}=3$, 5 , and 7) for templates of butyl-, hexyl-, and octylamines, respectively. Solid-state ${ }^{27} \mathrm{Al}$ and 31P MAS NMR spectra showed that both elements were in tetrahedral coordination. FT-IR spectra and ion-exchange studies revealed that three of the tetrahedra oxygen are bridging between $\mathrm{Al}$ and $\mathrm{P}$ atoms. The fourth oxygen, pointing away from the aluminophosphate sheet, bears either a proton when adhering to aluminum or an alkylammonium ion when adhering to phosphorus. The alkylammonium ions are ready for ion-exchange, while the protons attached to the $\mathrm{Al}-\mathrm{O}$ terminals are not exchangeable with alkaline ions. Similar to kanemite of single-layered structure, the aluminophosphate layers are able to reorganize and condense to form porous materials when the interlayer alkylammonium ions are exchanged by surfactant cations.
\end{abstract}

\section{Introduction}

The discovery of a series of microporous aluminophosphates by Wilson et al. ${ }^{1,2}$ in 1982 opened up the new possibility in designing new materials for sorption and catalysis. By varying the templates and the synthesis conditions, aluminophophates of profoundly different porous structures have been prepared. Some of them are structurally the same as naturally occurring or synthetic al uminosilicate zeolites, e.g., AIPO-17 is an isostructural anal ogue to erionite, AIPO-20 to sodal ite, and AIPO-34 to chabazite; however, many are new structures. Typically, the structure of these AIPO-based molecular sieves can be related to three-dimensional networks in which alternating $\mathrm{AlO}_{4}$ and $\mathrm{PO}_{4}$ tetrahedra are interconnected via oxygen atoms. The empirical formulas of these aluminophosphate compounds without considering the neutral template species trapped in the pores are $\mathrm{AlPO}_{4}$, which is isoelectronic to $\mathrm{SiO}_{2}$. The frameworks of aluminophosphate molecular sieves therefore are electroneutral and the compounds basically have no ion-exchange capacity. In the context of catalysis, negative charges have been introduced into the network by replacing a portion of phosphorus or aluminum in the framework by silicon or other cations of lower oxidation states. ${ }^{3-5}$ As a result, the possibility of ion exchange is created and the positive counterions present in the extraframework which balance the charges can provide acid-base functions.

\footnotetext{
* Corresponding author.

${ }^{\otimes}$ Abstract published in Advance ACS Abstracts, August 1, 1997.

(1) Wilson, S. T.; Lok, B. M.; Messing, C. A.; Cannan, T. R.; Flanigen, E. M. J . Am. Chem. Soc. 1982, 104, 1146.

(2) Wilson, S. T.; Lok, B. M.; Flanigen, E. M. U.S. Patent 4, 310, 440, 1982

(3) Lok, B. M.; Messina, C. A.; Patton, R. L.; Gajek, R. T.; Cannon, T. R.; Flanigen, E. M. U.S. Patent 4,440,871, 1984.

(4) Wilson, S. T.; Flanigen, E. M. Eur. Patent 132708, 1985.

(5) Wilson, S. T.; Flanigen, E. M. U.S. Patent 4,567,029, 1986.
}

Although the three-dimensional framework aluminophosphates have received most of the attention, in recent years several structures of one- and twodimensionally extended aluminophosphate solids have also been reported. ${ }^{6-17}$ Different from the threedimensional framework aluminophosphates, which have essentially atomic P/AI ratios of 1 , most of the one-and two-dimensionally extended aluminophosphates reported up to date have the atomic P/AI ratios greater than 1. Although the variation of the sheet structures in layered aluminophosphates is as vivid as that in three-dimensional framework, to the best of our knowledge, none of them is isostructural to naturally occurring or synthetic layered silicates. The present paper is concerned with a novel layered aluminophosphate, named AIPO-ntu, in which both aluminum and phosphorus are tetrahedrally coordinated with the atomic P/AI ratio of 1 and the sheet structure mimicked to

(6) J ones, R. H.; Thomas, J . M.; Xu, R.; Huo, Q.; Xu, Y.; Cheetham, A. K.; Bieber, D. J. Chem. Soc., Chem. Commun. 1990, 1170.

(7) Tieli, W.; Long, Y.; Wenqin, P. J. Solid State Chem. 1990, 89, 392.

(8) J ones, R. H.; Thomas, J. M.; Xu, R.; Huo, Q.; Cheetham, A. K.; Powell, A. V. J . Chem. Soc., Chem. Commun. 1991, 1266.

(9) Thomas, J . M.; J ones, R. H.; Xu, R.; Chen, J .; Chippindale, A. M.; Natarajan, S.; Cheetham, A. K.; J . Chem. Soc., Chem. Commun. $1992,929$.

(10) Chippindale, A. M.; Powell, A. V.; Bull, L. M.; J ones, R. H.; Cheetham, A. K.; Thomas, J. M.; Xu, R. J . Solid State Chem. 1992, 96, 199.

(11) Kuperman, A.; Nadimi, S.; Oliver, S.; Ozin, G. A.; Garces, J . M.; Olken, M. M. Nature, 1993, 365, 239.

(12) J ones, R. H.; Chippindale, A. M.; Natarajan, S.; Thomas, J . M. J . Chem. Soc., Chem. Commun. 1994, 565.

(13) Morgan, K.; Gainsford, G.; Milestone, N. J . Chem. Soc., Chem. Commun. 1995, 425.

(14) Barrett, P. A.; J ones, R. H. J . Chem. Soc., Chem. Commun. 1995, 1979.

(15) Bruce, D. A.; Wilkinson, A. P.; White, M. G.; Bertrand, A. J Chem. Soc., Chem. Commun. 1995, 2059.

(16) Oliver, S.; Kuperman, A.; Lough, A.; Ozin, G. J . Chem. Soc., Chem. Commun. 1996, 1761.

(17) Sayai, A.; Karra, V. R.; Reddy, J. S.; Moudrakovski, I. L. J Chem. Soc., Chem. Commun. 1996, 411. 
naturally occurring kenamite mineral. Kanemite has an idealized formula of $\mathrm{NaHSi}_{2} \mathrm{O}_{5} \cdot 3 \mathrm{H}_{2} \mathrm{O}$. The discovery of this alkali silicate mineral at Kanem, Lake Chad, was described by J ohan and Maglione. ${ }^{18}$ Later, various methods for the synthesis of kanemite were described by Beneke and Lagaly. ${ }^{19}$ They also showed that kanemite has a layered structure, and the interlayer cations can be exchanged with a variety of organic cations. In the past few years, increasing attention has been received by kenamite because this layered silicate can either be used as starting material for preparing microporous materials through pillaring with silica 20 or transform to ordered mesoporous three-dimensional framework in the presence of alkyltrimethylammonium ions. ${ }^{21-24}$ The novel layered aluminophosphate prepared in this paper has the sheet structure and ionexchange properties very similar to kanemite. Its synthesis and chemical properties were examined.

\section{Experimental Section}

Synthesis of Layered Aluminophosphates. The mentioned compounds were synthesized based on the substrate composition of $\mathrm{Al}_{2} \mathrm{O}_{3}: \mathrm{P}_{2} \mathrm{O}_{5}:(1.7-2.0)$ n-alkylamine: $(25-70) \mathrm{H}_{2} \mathrm{O}$. To an aqueous suspension of pseudoboehmite powder (Vista, Catapal A, 73.5\% $\mathrm{Al}_{2} \mathrm{O}_{3}$ ), orthophosphoric acid (J anssen, 85\%) and water were added dropwise, followed by vigorous stirring for $2 \mathrm{~h}$. After the addition of n-alkylamine, either n-butyl, n-hexyl-, or n-octylamines (J anssen, reagent grade), the mixture was stirred for another $2 \mathrm{~h}$ or longer before it was loaded into Teflon-lined stainless steel autoclaves and heated at 180$200{ }^{\circ} \mathrm{C}$ for $48-72 \mathrm{~h}$. The resultant crystallites were washed with deionized water thoroughly and dried at $50^{\circ} \mathrm{C}$.

Characterization Techniques. The Al and $\mathrm{P}$ compositions of the resultant samples were analyzed with ICP-AES (Allied Analytical System, J arrell-Ash, Model IC AP 9000) using $\mathrm{HCl}$-dissolved solutions. The $\mathrm{C}, \mathrm{H}$, and $\mathrm{N}$ compositions were analyzed with a Perkin-EImer 2500 elemental analysis system. TGA was performed in $\mathrm{N}_{2}$ environment on a duPont 951 thermogravimetric analyzer. The powder XRD patterns were recorded with a Philips PW 1840 automated powder diffractometer, using $\mathrm{Ni}$-filtered $\mathrm{Cu} \mathrm{K} \alpha$ radiation. The SEM photographs were taken using a Hitachi S-2400 scanning electron microscopy. Both transmission and diffuse reflectance FT-IR spectra were taken with a Bomem MB 100 FTIR spectrometer. Solid-state ${ }^{27}$ AI MAS NMR spectra were taken with a Bruker MSL-500 spectrometer at a frequency of 130.32 $\mathrm{MHz}$, rotation speed of $5 \mathrm{kHz}$, pulse length of $3.0 \mathrm{~ms}$, recycling delay time of $1 \mathrm{~s}$, and a $1 \mathrm{M} \mathrm{AlCl}_{3}$ solution was used as external reference. Solid-state ${ }^{31} \mathrm{P}$ MAS NMR spectra were taken with a DMX-300 spectrometer at a frequency of $121.49 \mathrm{MHz}$, rotation speed of $5 \mathrm{kHz}$, pulse length of $7.0 \mathrm{~ms}$, recyding delay time of $30 \mathrm{~s}$, and a $85 \% \mathrm{H}_{3} \mathrm{PO}_{4}$ solution was used as external reference.

\section{Results and Discussion}

Structure Characterization. Figure 1 shows the $X$-ray powder diffraction patterns of the as-synthesized AIPO-ntu using n-alkylamines of different carbon chain

(18) J ohan, Z.; Maglione, G. F. Bull. Soc. Fr. Mineral. Cristallogr. 1972, 95, 371.

(19) Beneke, K.; Lagaly, G. Am. Mineral. 1977, 62, 763.

(20) Wong, S.-T.; Wong, S.-W.; Liu, S.-B.; Cheng, S. Stud. Surf. Sci. Catal. 1994, 84, 45.

(21) Yanagisawa, T.; Shimizu, T.; Kuroda, K.; Kato, C. Bull. Chem. Soc. J pn. 1990, 63, 1535.

(22) Inagaki, S.; Fukushima, Y.; Kuroda, K. Stud. Surf. Sci. Catal. 1994, 84, 125.

(23) Chen, C.-Y.; Xiao, S.-Q.; Davis, M. E. Microporous Mater. 1995, $4,1$.

(24) Inagaki, S.; Koiwai, A.; Suzuki, N.; Fukushima, Y.; Kuroda, K. Bull. Chem. Soc. J pn. 1996, 69, 1449.

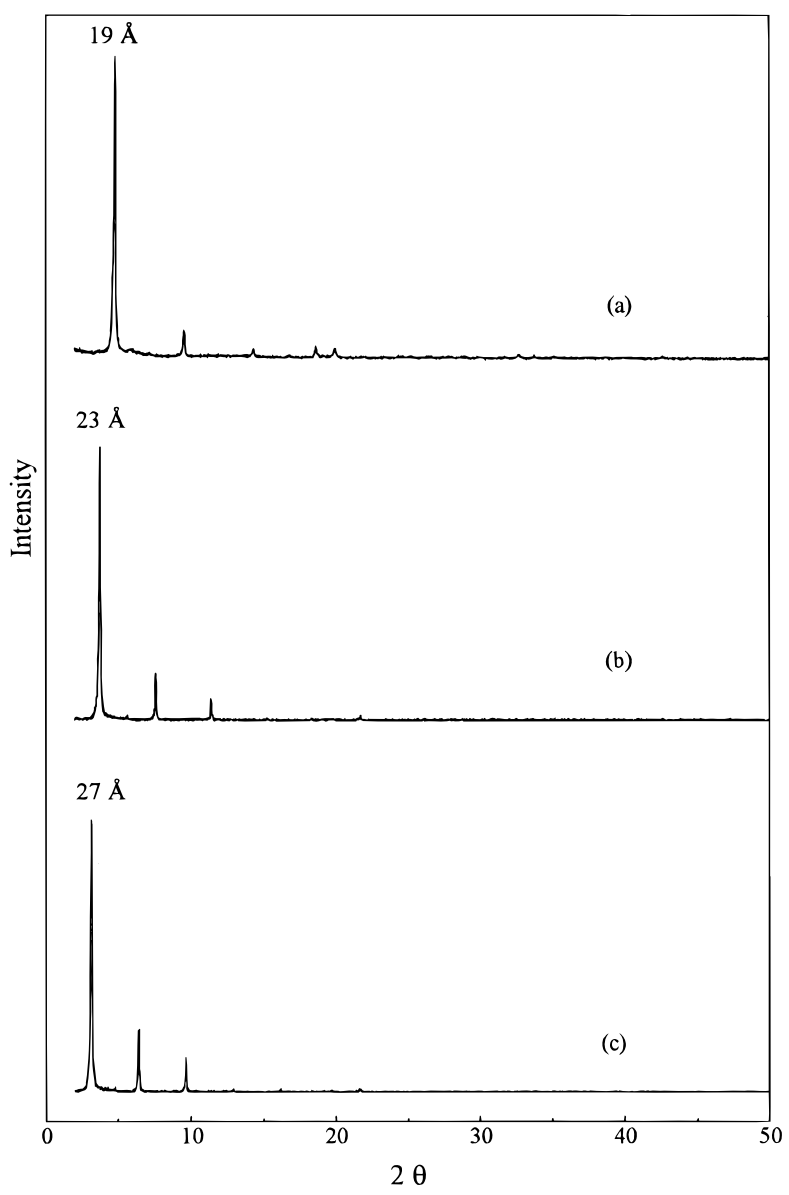

Figure 1. XRD patterns of as-synthesized AIPO-ntu with (a) n-butylamine, (b) n-hexylamine, and (c) octylamine as template.

lengths as templates. All three patterns predominantly consist of a series of peaks which have d spacings of the type $\mathrm{d}_{00} / \mathrm{l}$, wherel is an integer, and that is a strong indication of the occurrence of lamellar structures. The $\mathrm{d}$ spacings of the diffraction peaks at lowest $2 \theta$ vary from 19,23 , to $27 \AA$ with the carbon chain length increasing from butyl-, hexyl-, to octylamine, respectively. When plotting these $d$ spacings versus number of carbon atoms in n-alkylamines, a straight line with a gradient of $2.1 \AA$ A/carbon atom was obtained. Since alkyl chains grow by ca. $1.27 \AA$ per added carbon, the gradient suggests that the $n$-alkylamines form bilayers between the aluminophosphate sheets.

The crystallites of as-synthesized AIPO-ntu have the shape of an oval platelet and their sizes ranged from ca. 0.5 to $10 \mu \mathrm{m}$, as observed by SEM. The platelet shapes are commonly observed on compounds of layered structures. That also explains the preferred orientation of (00l) planes in the XRD patterns.

Figure $2 A, B$ show the ${ }^{27} \mathrm{Al}$ and ${ }^{31} \mathrm{P}$ MAS NMR spectra, respectively, of the as-synthesized AIPO-ntu. The spectra of the samples prepared with different n-alkylamines are all very similar and simple. Only one peak appears at $40 \mathrm{ppm}$ in ${ }^{27} \mathrm{AI}$ MAS NMR spectra, and only one at $-3.8 \mathrm{ppm}$ in 31P MAS NMR spectra. The chemical shift of ${ }^{27} \mathrm{AI}$ MAS NMR spectra is close to those of three-dimensional network aluminophosphates, in which tetrahedral coordinated Al appears at ca. 32-36 ppm. ${ }^{25,26}$ Hence, the single peak at 40 ppm indicates that all Al atoms in the as-synthesized AIPO-ntu 

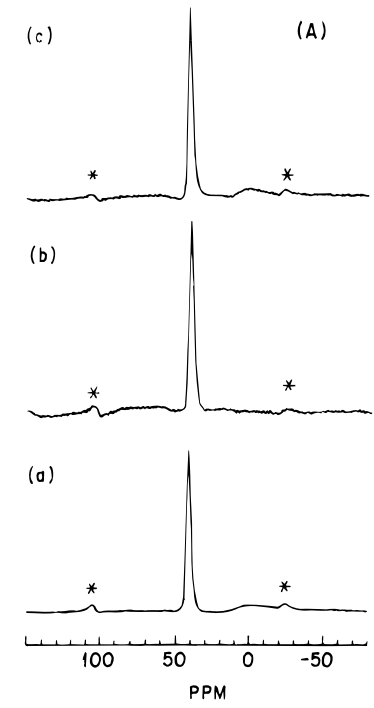

Figure 2. Solid-state (A) ${ }^{27} \mathrm{Al}$ and (B) ${ }^{31} \mathrm{P}$ MAS NMR spectra of as-synthesized AIPO-ntu with (a) n-butylamine, (b) nhexylamine, and (c) octylamine as template. The peaks with asterisks are spin sidebands.

samples are in the same tetrahedral coordination environment. But, the chemical shift of $-3.8 \mathrm{ppm}$ in ${ }^{31} \mathrm{p}$ MAS NMR spectra is very different from those observed on three-dimensional network aluminophosphates, where P usually appears at -15 to -33 ppm. ${ }^{25,26}$ Nevertheless, the single peak also implies that all $\mathrm{P}$ atoms in the assynthesized samples are in the same coordination environment.

The AIPO-ntu samples prepared with different nalkylamines also show very similar infrared spectra (Figure 3A). Absorptions below $1400 \mathrm{~cm}^{-1}$ are attributed to the lattice vibration of aluminophosphates, and an enlargement of this portion is shown in Figure 3B. Peaks at $950-1250$ and $600-900 \mathrm{~cm}^{-1}$ regions correspond to the asymmetric and symmetric stretching vibrations, respectively, of $\mathrm{TO}_{4}(\mathrm{~T}=\mathrm{Al}$ or $\mathrm{P})$ tetrahedra. Peaks at $400-500 \mathrm{~cm}^{-1}$ are due to $\mathrm{O}-\mathrm{T}-\mathrm{O}$ bending, and the peak at ca. $735 \mathrm{~cm}^{-1}$ is a combination of $\mathrm{Al}-\mathrm{O}$ and $\mathrm{P}-\mathrm{O}$ vibrations. ${ }^{27,28}$ However, it is noticeable that two strong absorptions appeared at 880 and $907 \mathrm{~cm}^{-1}$ for the layered AIPO-ntu were not observed in the spectra of aluminophosphates of three-dimensional framework. ${ }^{28,29}$ The alkyl groups of amines give strong absorptions in the regions $2850-3000$ and $1400-1600$ $\mathrm{cm}^{-1}$, which correspond to $\mathrm{C}-\mathrm{H}$ stretching and bending vibrations, respectively. Nevertheless, the appearance of the broad ammonium band overlapping over $\nu \mathrm{CH}$ band at ca. $3100 \mathrm{~cm}^{-1} 30$ implies that the $n$-alkylamines are present in the interlayer as alkylammonium ions instead of neutral molecules. On the other hand, a strong sharp absorption at $3580 \mathrm{~cm}^{-1}$ is apparently attributed to free $\mathrm{O}-\mathrm{H}$ groups, which were not reported on aluminophosphates of three-dimensional framework either. The AlO-H stretching absorptions were re-

(25) Meinhold, R. H.; Tapp, N. J . J . Chem. Soc., Chem. Commun. 1990, 219.

(26) Blackwell, C. S.; Patton, R. L. J . Phys. Chem. 1988, 92, 3965. (27) Arlidge, E. Z.; Farmer, V. C.; Mitchell, B. D.; Mitchell, W. A. J . Appl. Chem. 1963, 13, 17.

(28) Tapp, N. J .; Milestone, N. B.; Bowden, M. E.; Meinhold, R. H. Zeolites, 1990, 10, 105.

(29) Davis, M. E.; Montes, C.; Hathaway, P. E.; Arhancet, J . P.; Hasha, D. L.; Garces, M. J . Am. Chem. Soc. 1989, 111, 3919.

(30) Corbridge, D. E. C. J . Appl. Chem. 1956, 6, 456.

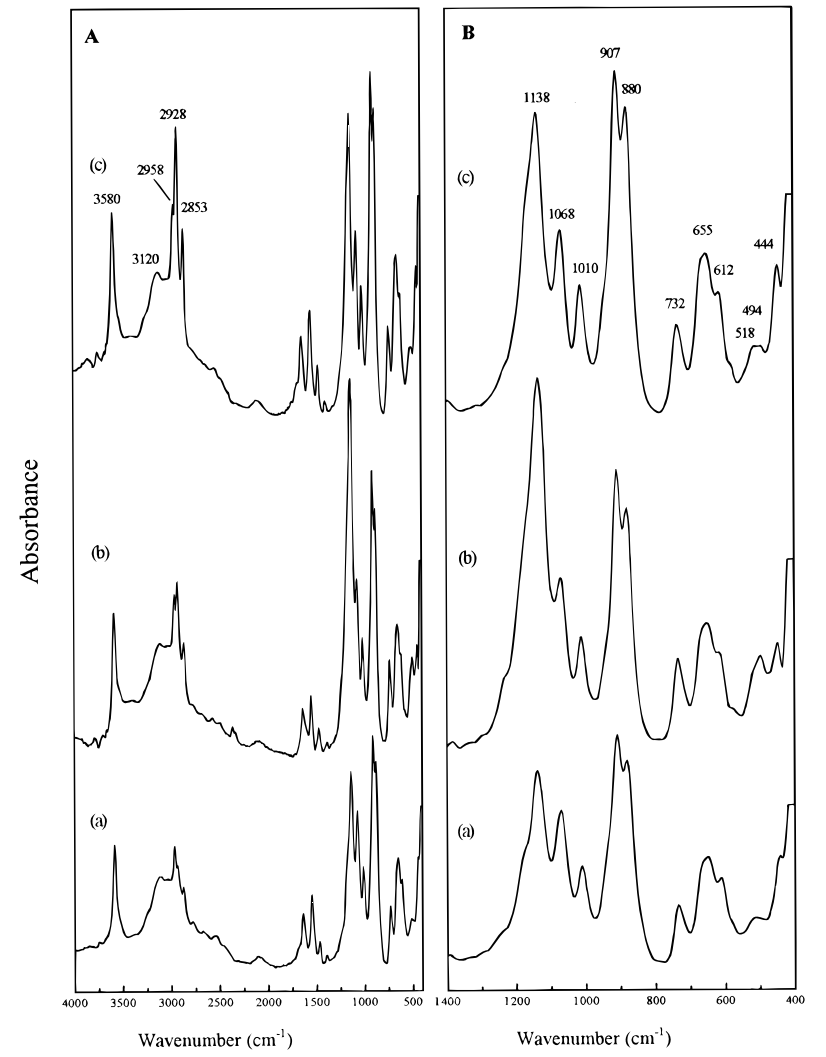

Figure 3. FT-IR spectra of as-synthesized AIPO-ntu with (a) n-butylamine, (b) n-hexylamine, and (c) octylamine as template.

ported to appear in the range ca. $3374-3620 \mathrm{~cm}^{-1}$, depending on the coordination environment around $\mathrm{Al}, 31,32$ but free $\mathrm{PO}-\mathrm{H}$ stretching usually appears at ca. $3675 \mathrm{~cm}^{-1}$. 28,29 Hence, the sharp peak at $3580 \mathrm{~cm}^{-1}$ is assigned to terminal AIO-H stretching.

The TGA profiles of the as-synthesized AIPO-ntu compounds show obvious weight losses started at ca. $200{ }^{\circ} \mathrm{C}$ (Figure 4). The weight losses as a function of temperature are tabulated in Table 1 . Because the amount of weight losses around $200-300^{\circ} \mathrm{C}$ is proportional to the carbon chain length of alkylamines, it is attributed mainly to the decomposition of interlayer alkylammonium ions. Consistently, the XRD study on the quenched samples showed that the structure of assynthesized AIPO-ntu was retained after heating the samples at $200{ }^{\circ} \mathrm{C}$, and it became amorphous after heating above $300{ }^{\circ} \mathrm{C}$. The slight weight losses at temperatures lower than $120^{\circ} \mathrm{C}$ are considered due to the release of physically adsorbed water molecules since the amount is proportional to the hydrophilicity of the alkylamines. On the other hand, the extending weight losses at temperatures higher than $320^{\circ} \mathrm{C}$ are probably a result of slow desorption of decomposed carbon residues.

Figure 5 is the ${ }^{27} \mathrm{Al}$ and ${ }^{31} \mathrm{P}$ solid-state NMR spectra of AIPO-ntu, prepared with butylamine as template, after heating the sample at various temperatures. Only one peak centered at $40 \mathrm{ppm}$ was seen in the ${ }^{27} \mathrm{Al} \mathrm{NMR}$ spectra, and the peak became broader after the samples were calcined at higher temperatures. Little informa-

(31) Namkung, J . S.; Hoke, M.; Rogowski, R. S.; Albin, S. Appl. Spectrosc. 1995, 49, 1305.

(32) Dutta, P. K.; Robins, D. S. Langmuir 1994, 10, 4681. 

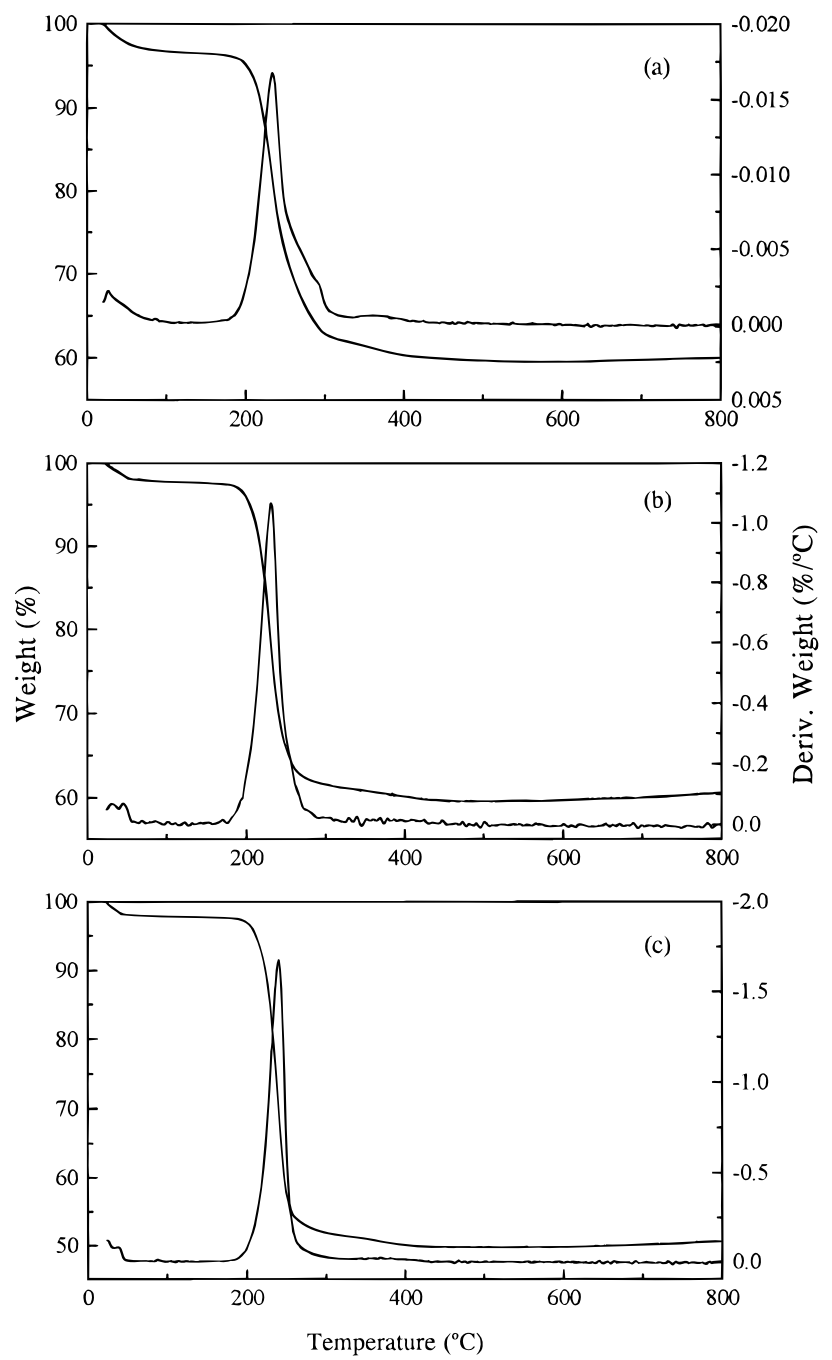

Figure 4. TGA profiles of as-synthesized AIPO-ntu with (a) n-butylamine, (b) n-hexylamine, and (c) octylamine as template.

Table 1. TGA Data of Layered Aluminophosphates under Nitrogen Atmosphere

\begin{tabular}{cccc}
\hline sample & temp range $\left({ }^{\circ} \mathrm{C}\right)$ & wt loss (\%) & total wt loss (\%) \\
\hline AIPO-ntu-4 $^{\text {a }}$ & $25-128$ & 2.4 & 37.7 \\
& $194-318$ & 33.0 & \\
AIPO-ntu-6 & $318-800$ & 2.3 & \\
& $25-124$ & 2.2 & 41.4 \\
& $206-323$ & 37.2 & \\
AlPO-ntu-8 & $323-800$ & 2.0 & 50.7 \\
& $25-105$ & 1.2 & \\
& $214-337$ & 46.3 & \\
& $337-800$ & 3.2 &
\end{tabular}

a The carbon numbers of $n$-alkylamines used as template.

tion can be drawn from the spectra due to the strong quadrupolar interaction between ${ }^{27} \mathrm{Al}$ nuclei of $\mathrm{I}=5 / 2$, except confirming that the $\mathrm{Al}$ atoms remain in tetrahedral coordination. In contrast, there is an obvious shift from -3.6 to $-26.4 \mathrm{ppm}$ and broadening of the peak in the ${ }^{31}$ P NMR spectra after AIPO-ntu was heated at temperatures above $300{ }^{\circ} \mathrm{C}$. Since the ${ }^{31} \mathrm{P}$ NMR signals of aluminophosphate of three-dimensional frame work usually appear at -19 to $-30 \mathrm{ppm},{ }^{26}$ these results indicate that the layered structure of AIPO-ntu is destroyed and the compound transforms to a threedimensional network after interlayer amine species have been removed through heating. The resultant compound was found to beX-ray amorphous, which was
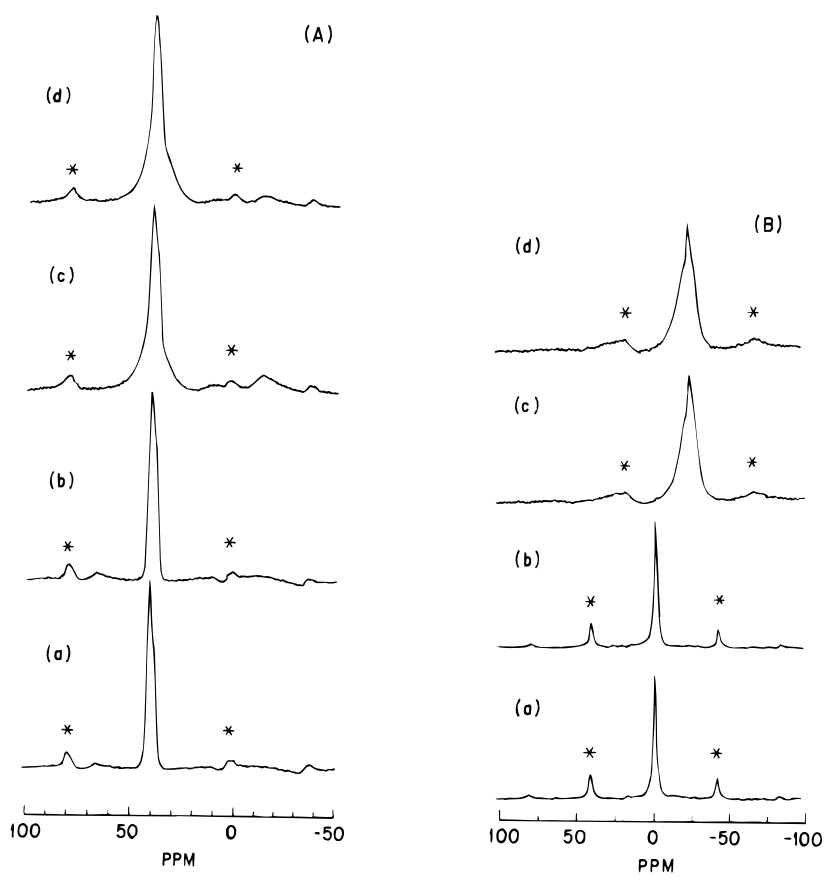

Figure 5. Solid-state $(A){ }^{27} \mathrm{Al}$ and $(B){ }^{31} \mathrm{P}$ MAS NMR spectra of AIPO-ntu-4 (a) as-synthesized, and after calcination at (b) 200, (c) 400 , and (d) $600^{\circ} \mathrm{C}$. The peaks with asterisks are spin sidebands.

al so reflected by the broadness of the peaks in the NMR spectra. Hence, the crystal nature of this condensed phase could not be resolved. Nevertheless, the shift of the ${ }^{31} \mathrm{P}$ NMR peak from -3.6 to $-26.4 \mathrm{ppm}$, which is where aluminophosphates of three-dimensional framework usually appear, implies that the condensation is probably through the formation of $\mathrm{Al}-\mathrm{O}-\mathrm{P}$ linkage between the sheets. Another remark about the ${ }^{31 P}$ NMR is that the $-3.6 \mathrm{ppm}$ peak observed on the layered structures may be assigned to the " $\mathrm{Q}_{3}$ " phosphorus or the ${ }^{-} \mathrm{OP}(\mathrm{OAI})_{3}$ unit with a terminal $\mathrm{P}-\mathrm{O}$ group, in contrast to that at -26.4 ppm for the " $\mathrm{Q}_{4}$ " phosphorus or the $\mathrm{P}(\mathrm{OAI})_{4}$ unit.

The chemical compositions of the as-synthesized AIPO-ntu were determined with ICP-AES and C, H, N analyzer. On the basis of the analytical data (Table 2), the empirical formulas are in the form $\mathrm{AlPO}_{3}$ $(\mathrm{OH})_{2}\left[\mathrm{NH}_{2}\left(\mathrm{CH}_{2}\right)_{n} \mathrm{CH}_{3}\right]$, where $\mathrm{n}=3,5$ or 7 for butyl-, hexyl-, and octylamines, respectively. It is noticeable that the atomic ratios of $\mathrm{Al}: \mathrm{P}: \mathrm{N}$ are all around $1: 1: 1$. Since NMR spectra show that both $A I$ and $P$ are in tetrahedral coordination and the IR study indicates the presence of alkylammonium ions as well as free $\mathrm{AlO}-\mathrm{H}$ groups, the chemical formulas are better stated as $\mathrm{Al}(\mathrm{OH}) \mathrm{P}\left[\mathrm{O}^{-}{ }^{+} \mathrm{NH}_{3}\left(\mathrm{CH}_{2}\right)_{n} \mathrm{CH}_{3}\right] \mathrm{O}_{3}$. In other words, the interlayer alkylamines are forming alkylammonium ions and attached to the terminal $\mathrm{P}-\mathrm{O}$ groups. This is reasonable in considering that the protons in $\mathrm{P}-\mathrm{OH}$ groups are more acidic than those in $\mathrm{Al}-\mathrm{OH}$. As a result, the $\mathrm{P}-\mathrm{OH}$ groups were not seen. I nstead, the neutralized product of alkylammonium ions are formed and attached to the $\mathrm{P}-\mathrm{O}^{-}$terminals through electrostatic interaction.

Ion-Exchange Properties. The interlayer alkylammonium ions were further confirmed by ion-exchange with alkali ions. A $0.3 \mathrm{~g}$ portion of the AIPO-ntu compounds was stirred with $50 \mathrm{~mL}$ of $1 \mathrm{M} \mathrm{NaCl}$ or $\mathrm{KCl}$ solution for 3 days, followed by washing with 95\% 
Table 2. Elemental Analysis Results of As-Synthesized Layer Aluminophosphates

\begin{tabular}{|c|c|c|c|c|c|c|c|c|}
\hline sample & & $P$ & $\mathrm{Al}$ & $\mathrm{C}$ & $\mathrm{H}$ & $\mathrm{N}$ & $\mathrm{O}$ & assigned formula \\
\hline \multirow[t]{2}{*}{ AIPO-ntu-4 } & wt ratio & 1.51 & 1.26 & 2.19 & 0.57 & 0.62 & 4.34 & \\
\hline & molar ratio & 1.09 & 1.05 & 4.11 & 12.9 & 1 & 5.10 & $\mathrm{AlPO}_{3}(\mathrm{OH})_{2}\left(\mathrm{NH}_{2} \mathrm{C}_{4} \mathrm{H}_{9}\right)$ \\
\hline \multirow[t]{2}{*}{ AIPO-ntu-6 } & wt ratio & 1.02 & 0.98 & 2.36 & 0.54 & 0.45 & 3.83 & \\
\hline & molar ratio & 1.03 & 1.03 & 6.15 & 16.9 & 1 & 5.50 & $\mathrm{AlPO}_{3}(\mathrm{OH})_{2}\left(\mathrm{NH}_{2} \mathrm{C}_{6} \mathrm{H}_{13}\right)$ \\
\hline \multirow[t]{2}{*}{ AIPO-ntu-8 } & wt ratio & 1.21 & 1.06 & 3.29 & 0.73 & 0.47 & 3.35 & \\
\hline & molar ratio & 1.16 & 1.17 & 8.16 & 21.6 & 1 & 5.22 & $\mathrm{AlPO}_{3}(\mathrm{OH})_{2}\left(\mathrm{NH}_{2} \mathrm{C}_{8} \mathrm{H}_{17}\right)$ \\
\hline
\end{tabular}

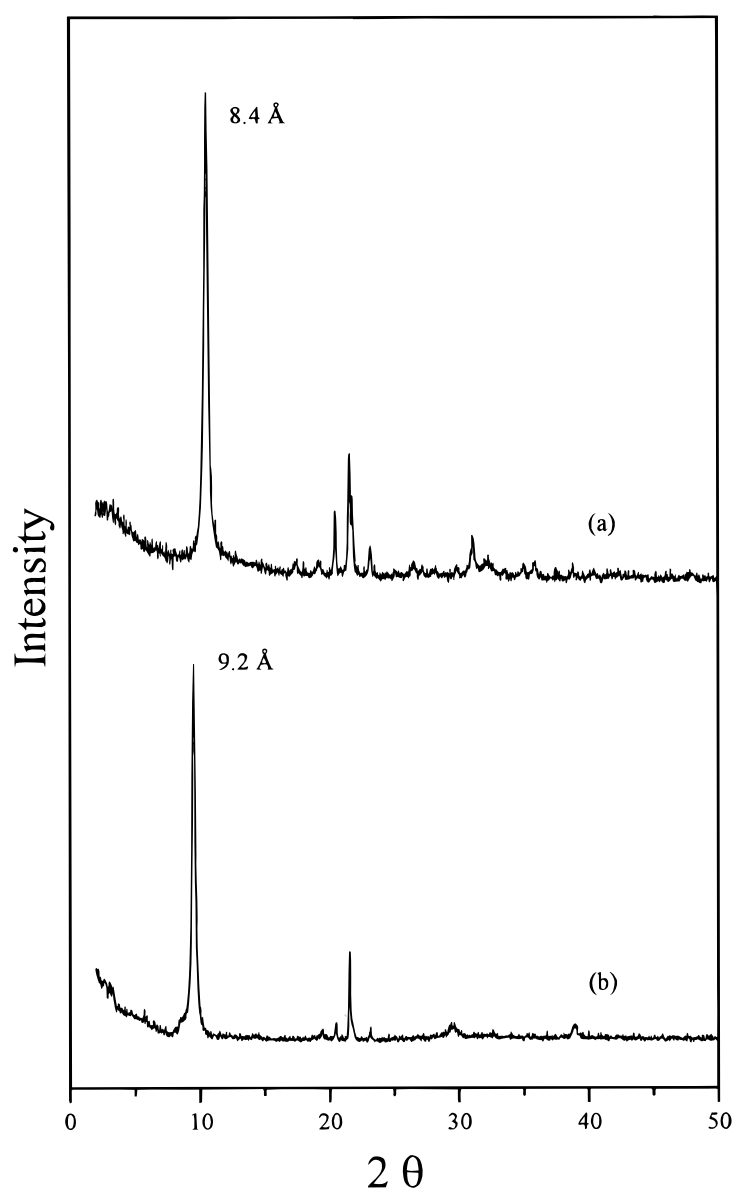

Figure 6. XRD patterns of (a) $\mathrm{Na}^{+}$- and (b) $\mathrm{K}^{+}$-exchanged AIPO-ntu.

alcohol and drying at $50^{\circ} \mathrm{C}$. Figure 6 shows that the $d$ spacings shrink to 8.4 and $9.2 \AA$, respectively, for $\mathrm{Na}^{+}$and $\mathrm{K}^{+}$-exchanged products, and these changes are independent of the amines originally incorporated in AIPO-ntu. By subtracting the diameters of $\mathrm{Na}^{+}$and $\mathrm{K}^{+}$ ions ( 2.0 and $2.7 \AA$, respectively) from the $d$ spacings, a layer thickness of ca. $6.4 \AA$ is obtained. The strongest lines of the X-ray powder pattern of $\mathrm{Na}$-AIPO-ntu are 8.4 (10), 4.36 (3), 4.14 (4), 3.86 (2), and 3.00 (1) A.. Again, the preferred orientation of the (00I) planes, which likely correspond to peaks at 8.4 and $4.14 \AA$, was observed on the pattern. The interlayer distance of $8.4 \AA$ is smaller than $10.3 \AA$ reported for kanemite with $2-3$ hydrated waters per formula. However, that of the dehydrated kanemite can shrink to 7.73-6.35 $\AA .{ }^{18}$ Hence, the interlayer distances obtained for $\mathrm{Na}^{+}$- and $\mathrm{K}^{+}$-exchanged AIPO-ntu are in the reasonable range as those for monophyllosilicates made of single tetrahedra layer.

Elemental analysis of the $\mathrm{Na}^{+}$-exchanged AIPO-ntu shows the atomic ratio of $\mathrm{Al}: \mathrm{P}: \mathrm{Na}: \mathrm{N}$ to be around 1.00: 0.91:0.89:0.05, confirming that most of the interlayer alkylammonium ions have been exchanged by $\mathrm{Na}^{+}$ions. The resultant compound has a chemical formula close to $\mathrm{NaHAlPO}_{5} \cdot \mathrm{XH}_{2} \mathrm{O}$, which is mimicked to that of kanemite, idealized $\mathrm{NaHSi}_{2} \mathrm{O}_{5} \cdot 3 \mathrm{H}_{2} \mathrm{O}$.

Structure of AIPO-ntu Layer. Although the crystal structure of kanemite has not been determined, results from ${ }^{29} \mathrm{Si}$ MAS NMR spectra and X-ray diffractographs indicate it to be a thin layered polysilicate. ${ }^{33}$ Each layer of kanemite is made of a single sheet of $\mathrm{SiO}_{4}$ tetrahedra and all the $\mathrm{Si}$ atoms are confirmed by the ${ }^{29} \mathrm{Si} \mathrm{NMR}$ spectra to be in $\mathrm{Q}_{3}(\mathrm{Na}, \mathrm{H}) \mathrm{OSi}(\mathrm{OSi})_{3}$ environment. Most of the silicates with layer structures are formed of six-membered rings of tetrahedra, and only in very rare examples are based on alternative four- and eight-membered rings of tetrahedra. ${ }^{34}$ In the known structures of a potassium hydrogen silicate $\left(\mathrm{KHSi}_{2} \mathrm{O}_{5}\right)$ and the silicic acid $\left(\mathrm{H}_{2} \mathrm{Si}_{2} \mathrm{O}_{5}\right)$, each silicon atom shares three oxygen atoms with other $\mathrm{Si}$ atoms to form six-Siatom rings and extend indefinitely in two dimensions. ${ }^{35}$ Different from the silicate structure in talc, which has unshared oxygens pointed in the same direction, the single-sheet silicate has them pointed toward both sides of sheet. There are two ways to arrange the Si atoms. When the six Si atoms in a ring are arranged in the chair form, the unshared oxygens are pointing alternatively up and down the sheet. When the rings are in boat form, the unshared oxygens are pointing toward different directions in pair. Because both $\mathrm{KHSi}_{2} \mathrm{O}_{5}$ and $\mathrm{H}_{2} \mathrm{Si}_{2} \mathrm{O}_{5}$ have the latter structure, Apperley et al. ${ }^{33}$ boldly proposed the structure of the kanemite sheet to be similar.

Because solid-state NMR results show both $A I$ and $P$ are in a single coordination environment, the lamellar structure of AIPO-ntu is likely similar to that of kanemite or $\mathrm{KHSi}_{2} \mathrm{O}_{5}$. Al and $\mathrm{P}$ shall arrange alternatively in the sheet formed of six-membered rings of tetrahedra, and each ring consists of three $\mathrm{Al}$ and three $\mathrm{P}$ atoms. The schematic representation of the proposed structure is shown in Figure 7. In which, the six-T-member rings are in boat form and the unshared oxygen atoms in pairs, bonded to adjacent $\mathrm{Al}$ and $\mathrm{P}$, point toward different sides alternatively. If the rings are in chair form, the unshared oxygens bonded to Al will point toward one side and those bonded to $\mathrm{P}$ toward the other side. In such an arrangement, either the alkylammonium ions adhered to $\mathrm{P}-\mathrm{O}$ terminals could no longer form bilayers in the as-synthesized AIPO-ntu, or the Al$\mathrm{OH}$ terminals from adjacent two aluminophosphate sheets would face each other and result in a thick sheet more than twice the thickness of a single sheet. These are conflicted from what has been observed. Therefore, the lamellar structure of AIPO-ntu is most likely similar to that of kanemite or $\mathrm{KHSi}_{2} \mathrm{O}_{5}$. The other possibility that the AIPO-ntu sheet is formed of alternative four-

(33) Apperley, D. C.; Hudson, M. J .; Keene, M. T. J .; Knowles, J. A. J . Mater. Chem. 1995, 5, 577.

(34) Wells, A. F. In Structural Inorganic Chemistry; Clarendon Press: London, 1986; pp 787-808.

(35) Le Bihan, M. T.; Kalt, A.; Wey, R. Bull. Soc. Fr. Miner. Cristallogr. 1971, 94, 15. 
(a)

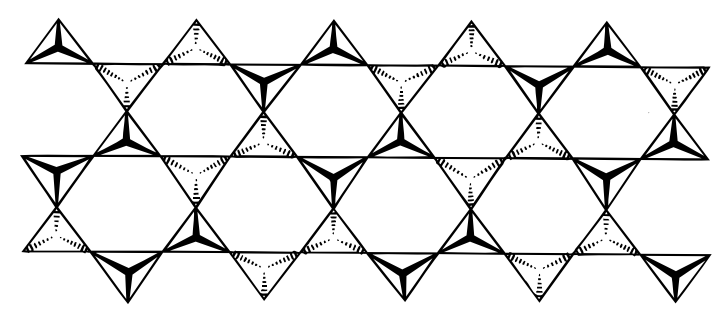

(b)

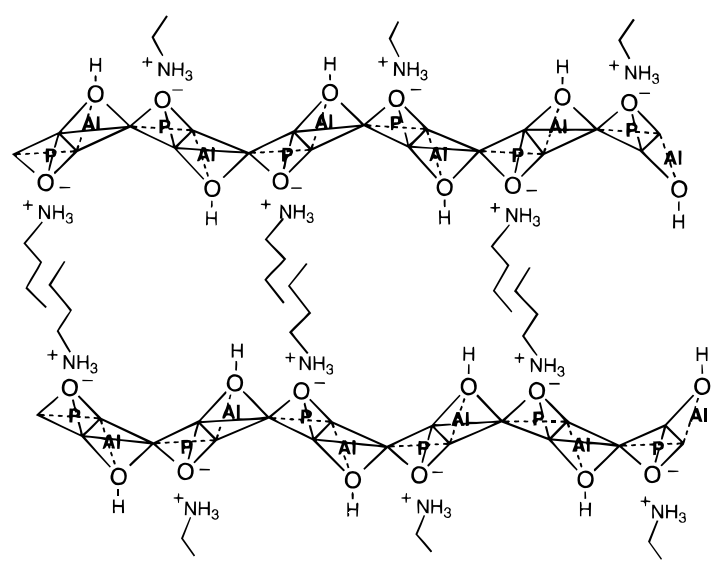

Figure 7. Schematic representation of (a) the layer projection of six-T-member ring and (b) the layer stacking in APO-ntu with butylamine in the interlayer.

and eight-membered rings of tetrahedra is also ruled out. In the known silicate examples, which are rare and the layers are held together by divalent cations, the vertexes of the tetrahedra in four-membered rings always point to the same side of the sheet. ${ }^{34}$ To form bilayers of alkylammonium ions, the vertexes of the tetrahedra in alternate four-rings have to point to opposite sides of the layer. In such an arrangement, either the $\mathrm{P}-\mathrm{O}$ terminals pointing in the same side of a sheet will distribute nonhomogeneously, and the resulting alkylammonium bilayer structure is not thermodynamically stable, or the eight-member rings have to fold into cubic shape and a thick layer of two fused tetrahedra thickness is resulted.

Properties of $\mathrm{Na}^{+}$-Exchanged AIPO-ntu. $\mathrm{Na}^{+}-$ exchanged AIPO-ntu shows better thermal stability than the alkylammonium precursors. The X-ray diffractographs demonstrate that although the crystallinity decreases with calcination temperature, the layered structure is well retained up to $300{ }^{\circ} \mathrm{C}$ (Figure 8). At $400{ }^{\circ} \mathrm{C}$, most of the characteristic peaks of $\mathrm{Na}$-AIPOntu nearly disappears, and at $600^{\circ} \mathrm{C}$, the compound was transformed to another crystalline structure with characteristic diffraction pattern similar to that of $\mathrm{Na}_{4} \mathrm{Al}_{5} \mathrm{H}_{8}-$ $\left(\mathrm{PO}_{4}\right)_{9} \cdot 10 \mathrm{H}_{2} \mathrm{O} .{ }^{36}$ The phase transformation as a function of temperature is also confirmed with in situ diffuse reflectance FT-IR spectroscopy. Figure 9 shows that the absorptions in aluminophosphate lattice vibration regi on have only little changes after the al kylammonium ions in AIPO-ntu were replaced by $\mathrm{Na}^{+}$ions. The splitting of the $1138 \mathrm{~cm}^{-1}$ peak into two at 1131 and $1191 \mathrm{~cm}^{-1}$ is probably a result of variation in $\mathrm{Al}-\mathrm{O}-\mathrm{P}$ angle. ${ }^{37}$ The same reason shall account for the merging

(36) Camondes, d'Yvoire, Boulle, C. R. Seances Acad. Sci., Ser. C 1968, 267, 1697.

(37) Holmes, A. J .; Kirkby, S. J .; Ozin, G. A.; Young, D. J . Phys. Chem. 1994, 98, 4677.

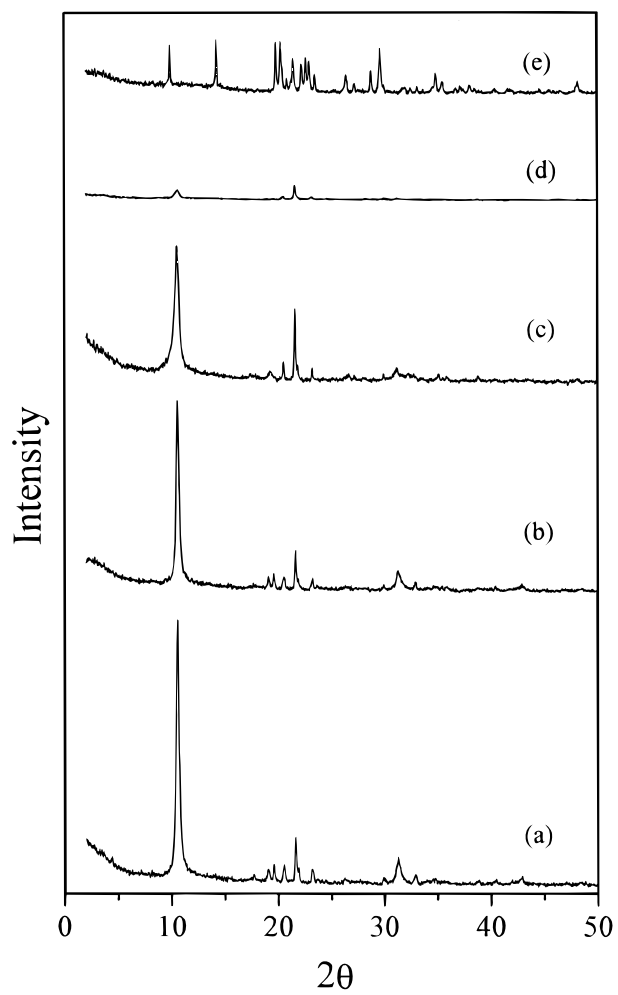

Figure 8. XRD patterns of $\mathrm{Na}^{+}$-exchanged AIPO-ntu (a) at room temperature and after calcination at (b) 200, (c) 300, (d) 400 , and (e) $600{ }^{\circ} \mathrm{C}$.

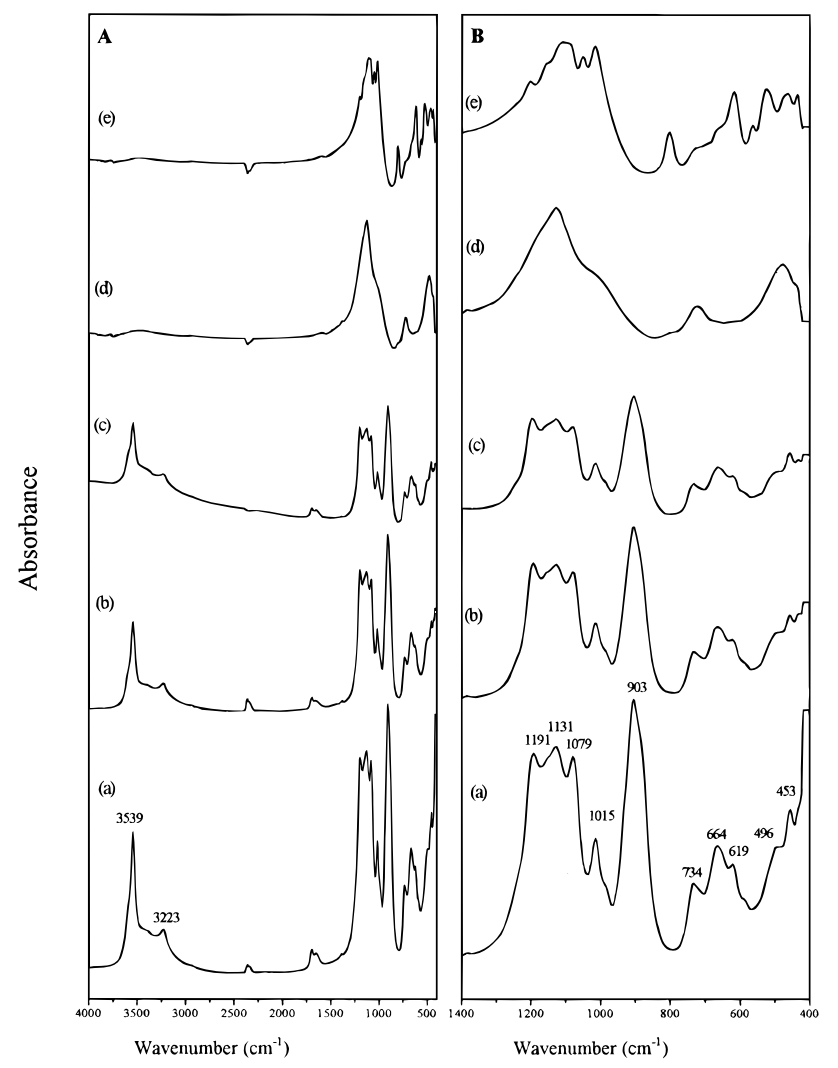

Figure 9. In situ diffused reflectance FT-IR spectra of $\mathrm{Na}^{+}$exchanged AIPO-ntu (a) at room temperature and after calcination at (b) 200, (c) 300, (d) 400, and (e) $600{ }^{\circ} \mathrm{C}$.

of the two peaks at 880 and $907 \mathrm{~cm}^{-1}$ into one broad peak at $903 \mathrm{~cm}^{-1}$. These peaks became diffused and all merged into a broad band when the compound was calcined at $400^{\circ} \mathrm{C}$. At this temperature, an amorphous phase was observed with XRD. After calcination at 600 


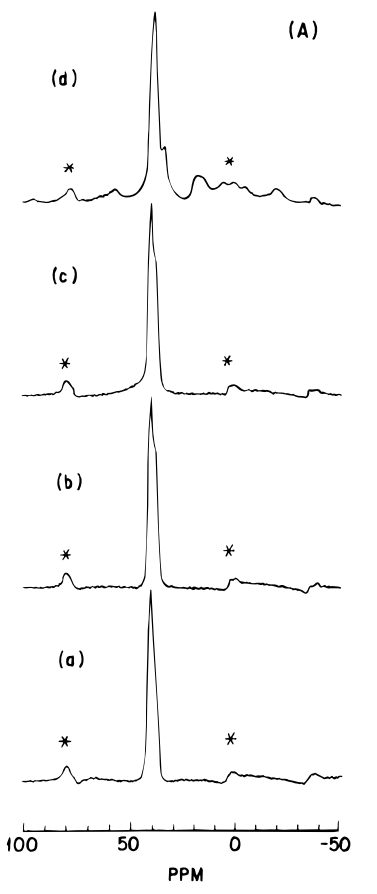

Figure 10. Solid-state $(A){ }^{27} \mathrm{Al}$ and $(B){ }^{31} \mathrm{P}$ MAS NMR spectra of $\mathrm{Na}^{+}$-exchanged AIPO-ntu (a) at room temperature, and after calcination at (b) 200 , (c) 400 , and (d) $600{ }^{\circ} \mathrm{C}$. The peaks with asterisks are spin sidebands.

${ }^{\circ} \mathrm{C}$, some sharp peaks appear again in the IR spectrum, as XRD confirms the formation of new crystalline phase. With the exchange of alkylammonium ions by $\mathrm{Na}^{+}$ions, the ammonium band at ca. $3100 \mathrm{~cm}^{-1}$ as well as the absorptions of $\mathrm{C}-\mathrm{H}$ stretching and bending disappear. However, the strong sharp absorption of free AlO-H stretching still remains except a slight shift from 3580 to $3540 \mathrm{~cm}^{-1}$, up to a calcination temperature of 400 ${ }^{\circ} \mathrm{C}$. The shift is proposed due to that the $\mathrm{AlO}-\mathrm{H}$ group may form hydrogen bond to adjacent alkylammonium ion through oxygen in the as-synthesized AIPO-ntu, while this $\mathrm{H}$ bond is no longer present when the alkylammonium ion is replaced by $\mathrm{Na}^{+}$. These results along with that of elemental analysis imply that the protons adhered to $\mathrm{Al}-\mathrm{O}$ terminals are not exchangeable with alkali ions. Besides, the IR studies also show that the dehydroxylation of these $\mathrm{AlO}-\mathrm{H}$ groups in $\mathrm{Na}-$ AIPO-ntu is completed at around $400^{\circ} \mathrm{C}$.

The structural changes of AIPO-ntu after $\mathrm{Na}^{+}$-ion exchange and through heat treatment are well revealed in the ${ }^{31 P}$ NMR spectra, while the ${ }^{27} \mathrm{Al}$ NMR spectra demonstrate that all $\mathrm{Al}$ atoms remain tetrahedrally coordinated (Figure 10). $\mathrm{Na}^{+}$-exchanged AIPO-ntu gives mainly a strong signal at $-4.5 \mathrm{ppm}$ in the ${ }^{31} \mathrm{P}$ NMR spectra, in addition to two small peaks at -25.0 and $-29.4 \mathrm{ppm}$. The main peak corresponds to phosphorus in $\mathrm{Q}_{3}$ environment. The results confirm that the sheet structure is retained after $\mathrm{Na}^{+}$-exchange. The slight upfield shift from -3.6 to -4.5 ppm is probably due to the stronger polarizability of $\mathrm{Na}^{+}$ion in comparison to that of alkylammonium ion. On the other hand, the two small peaks at -25.0 and -29.4 ppm shall correspond to phosphorus in $\mathrm{Q}_{4}$ environments. The presence of these peaks implies that a small portion of the sheet structures probably forms cross-link during $\mathrm{Na}^{+}$ionexchange reaction. The ease in interlayer linkage is common to thin-layer compounds, such as kanemite, due to the high flexibility of the sheet. These two $\mathrm{Q}_{4}$ peaks
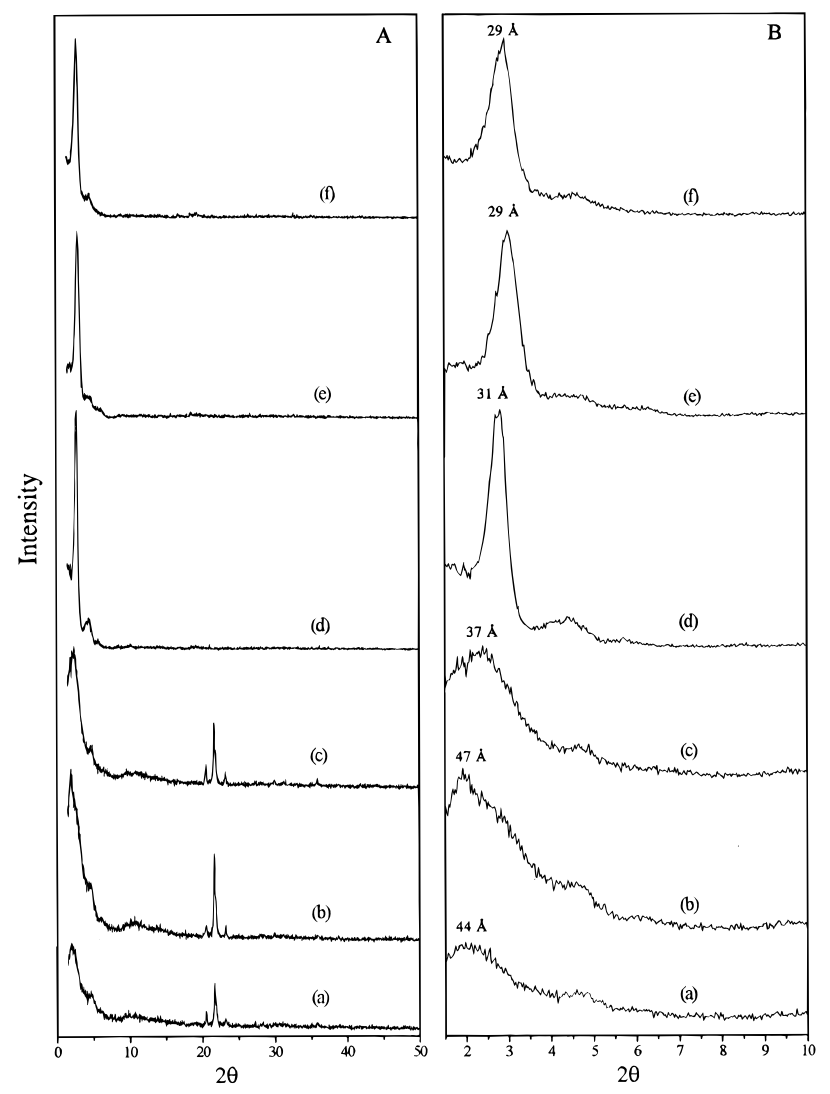

Figure 11. XRD patterns of AIPO-ntu after exchange with $\mathrm{C}_{16}$ TMA for various time periods: (a) 6 , (b) 12 , (c) 18 , (d) 20, (e) 30 , and (f) $40 \mathrm{~h}$.

grow strongly after the compound turns amorphous at $400^{\circ} \mathrm{C}$. At $600^{\circ} \mathrm{C}$, they diminish and another two sharp peaks appear at -3.0 and -11.8 ppm accompanied with the formation of a new crystalline phase.

Condensation of AIPO-ntu Layers in Solution of Organic Surfactant. The condensation behavior of AIPO-ntu in hexadecyltrimethylammonium chloride $\left(\mathrm{C}_{16} \mathrm{TMACl}\right)$ solution was compared to that of kanemite. A portion of $n-B^{-} N_{3}-$ AIPO-ntu was added to a $0.1 \mathrm{M}$ $\mathrm{C}_{16} \mathrm{TMACl}$ solution in 1:150 weight ratio. The suspension was stirred at $80^{\circ} \mathrm{C}$ for various periods of time. Figure 11 shows that the $d$ spacing corresponding to the lowest diffraction angle expands to ca. $44 \AA$ after 6 days. The distance increases further to $47 \AA$ after 12 days, then shrinks with time until a constant value of $29 \AA$ in 30 days. The variation of $d$ spacings and results of elemental analysis of the materials are tabulated in Table 3. The $47 \AA \mathrm{d}$ spacing was also reported for organic-kanemite materials prepared with $\mathrm{C}_{16}{ } \mathrm{TMA}{ }^{21,23}$ This peak is therefore assigned to AIPO-ntu containing $\mathrm{C}_{16} \mathrm{TMA}$ cations in the interlayer, which form a bilayer structure. Table 3 shows that the P/AI molar ratios in the samples remain close to one through the exchange period, while the N/P molar ratio reaches a maximum after 12 days and then decreases with lengthening of the exchange time up to 30 days. Since the solution has a $\mathrm{pH}$ value of 7 and therefore the proton concentration is very low, the only explanation for the change of elemental analysis data and the shrinkage of $d$ spacing after 12 days is that condensation of aluminophosphate layers occurs. Indeed, Figure 12 shows that the intensity ratio of characteristic lattice vibration of layered aluminophosphate around $900 \mathrm{~cm}^{-1}$ to that of bulk around $1100 \mathrm{~cm}^{-1}$ decreases slightly after AIPO-ntu was 
Table 3. Elemental Analysis Results and d Spacings of AIPO-ntu-4 after Exchange with $C_{16}$ TMA for Different Reaction Periods and Those after Posttreatment

\begin{tabular}{lccccc}
\hline \multirow{2}{*}{ samples } & $\begin{array}{c}\text { exchange time } \\
\text { (day) }\end{array}$ & $\begin{array}{c}\text { d spacing } \\
(\AA)\end{array}$ & \multicolumn{3}{c}{ molar composition } \\
\cline { 4 - 6 } & 6 & 44 & 0.353 & 1 & 1.07 \\
\hline ML-6 & 12 & 47 & 0.429 & 1 & 1.10 \\
ML-12 & 18 & 37 & 0.324 & 1 & 1.04 \\
ML-18 & 20 & 31 & 0.293 & 1 & 1.10 \\
ML-20 & 30 & 29 & 0.218 & 1 & 1.12 \\
ML-30 & 40 & 29 & 0.223 & 1 & 1.09 \\
ML-40 & & & & & \\
posttreatment & & & 0.015 & 1 & 1.12 \\
540-ML-40 & 3 & 22 & 0.018 & 1 & 1.10 \\
Na-ML-40 & 3 & 22 & 0.018 & 1 & 1.12 \\
H-ML-40c & 3 & &
\end{tabular}

a ML-40 after calcination at $540{ }^{\circ} \mathrm{C}$. ${ }^{\mathrm{b}} \mathrm{ML}-40$ after ion exchange with $\mathrm{Na}^{+}$. ${ }^{\mathrm{C}} \mathrm{ML}-40$ after ion exchange with $\mathrm{H}^{+}$.

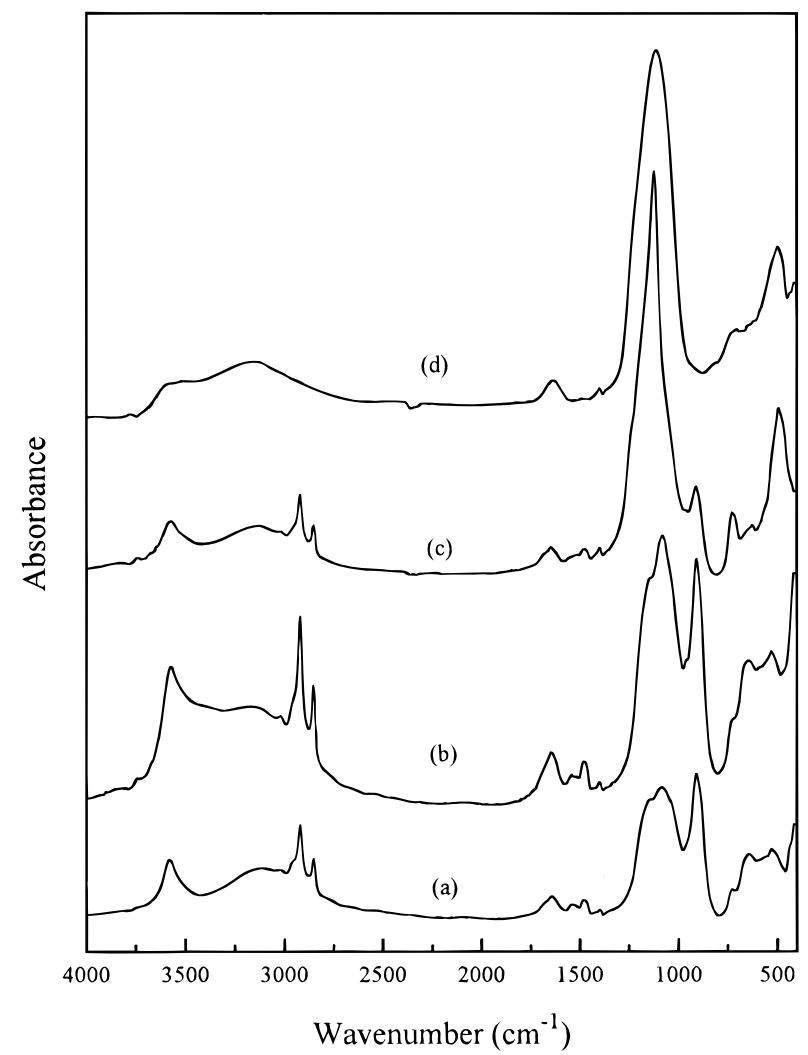

Figure 12. FT-IR spectra of AIPO-ntu exchanged with $\mathrm{C}_{16^{-}}$ TMA for various time periods: (a) 6 , (b) 18 , (c) 40 , and (d) sample ML-40 after calcination at $540^{\circ} \mathrm{C}$.

stirred in $\mathrm{C}_{16} \mathrm{TMACl}$ solution for 18 days. After longer exchange period, the former peak shrinks even markedly. These results al ong with the change of the XRD pattern demonstrate that the AIPO-ntu layers are reorganizing under the influence of the exchanged surfactant cations and transform to some kind of porous structure. Unfortunately, the resulting porous aluminophosphate compound is thermally unstable. Calcination at $540{ }^{\circ} \mathrm{C}$ to burn off the template molecules leads to collapse of the ordered structure and formation of a $X$-ray amorphous phase (Figure 13). Nevertheless, most of the template cations in ML-40 (AIPO-ntu after exchange with $\mathrm{C}_{16} \mathrm{TMA}$ for 40 days) could be removed by ion-exchange with $0.4 \mathrm{M}$ acetic acid in ethanol or with $3 \mathrm{M} \mathrm{NaCl}$ in $\mathrm{H}_{2} \mathrm{O}$ /ethanol (1:1 volumetric ratio) solution. The N/P molar ratios of the resultant compounds were found to decrease from 0.223 to ca. 0.018 (Table 3). The $\mathrm{d}$ spacings of both $\mathrm{H}^{+}$- and $\mathrm{Na}^{+}$-

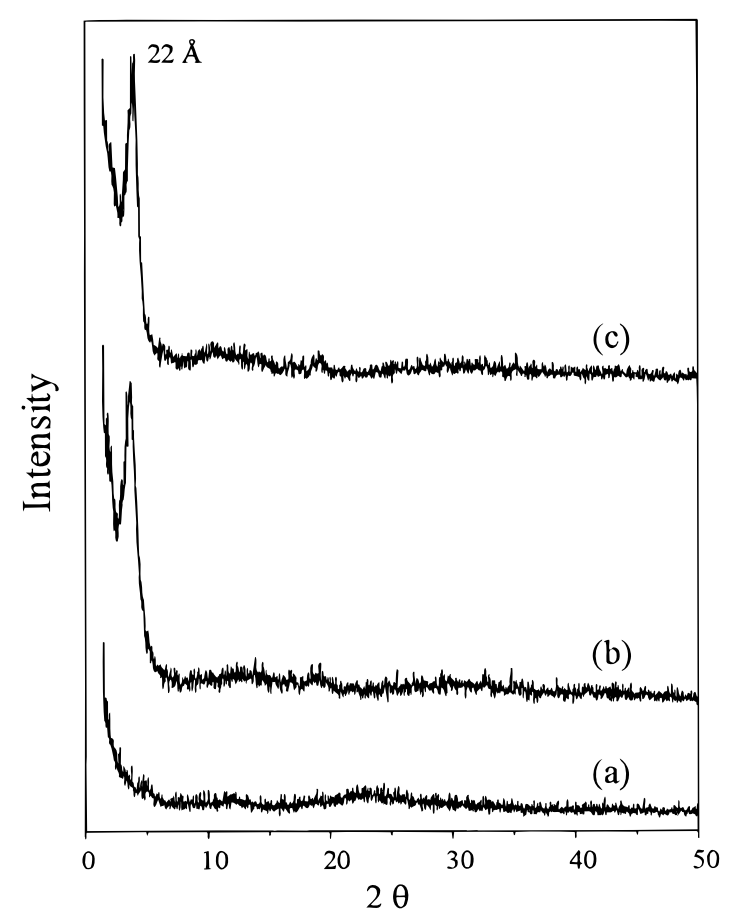

Figure 13. XRD patterns of ML-40 after (a) calcination at $540^{\circ} \mathrm{C}$, (b) $\mathrm{Na}^{+}$and (c) $\mathrm{H}^{+}$exchange.

exchanged ML-40 samples are similar and have values around $22 \AA$. The maintenance of the large $d$ spacing through $\mathrm{H}^{+}$- and $\mathrm{Na}^{+}$-ion exchange is further evidence that sample ML-40 is probably a porous network instead of a dense phase or a layered compound. However, the shrinkage of the d spacing value from 29 to $22 \AA$ indicates that further condensation of the framework occurs during the ion-exchange processes with ML-40. Unfortunately, the porous structures could not sustain thermal treatment at temperatures higher than $100^{\circ} \mathrm{C}$ before surface area measurement, and no hexagonal arrangement of tunneling pores as that of MCM-41 was detected on transmission electron micrographs.

For the formation of mesoporous materials from kanemite in solution of quaternary ammonium surfactant, Chen et al. ${ }^{23}$ proposed two mechanisms: one is the dissolution of silicate layers and the reconstruction of MCM-41 structure directed by the liquid-crystal template, the other is the reorganization of the kanemite layers driven by the structural change of exchanged surfactant cations from bilayer to cylindrical micelle and resulting in short-range hexagonal arrangement. Under our exchange condition, the solution has a $\mathrm{pH}$ of 7 and dissolution of aluminophosphate is considered to be negligible. Therefore, the second mechanism shall have greater possibility. However, the $d$ spacing of 29 $\AA$ obtained at final stage of condensation is much smaller than that of $44-47 \AA$ observed for mesoporous materials from kanemite. These results indicate that the condensation of aluminophosphate is not stopped at the stage of forming three-dimensional network around the cylindrical micelle. The less stability of aluminophosphate framework in comparison to that of silica is attributed to the higher polarity and less covalence of the $\mathrm{Al}-\mathrm{O}$ and $\mathrm{P}-\mathrm{O}$ bonds than $\mathrm{Si}-\mathrm{O}$ bond. The ease in framework rearrangement and condensation is also observed on other aluminophosphate molecular sieves. It is well-known that the VPI-5 molecular sieve, which is the aluminophosphate molecular 
sieve possessed the largest unidimensional channels known up to date, tend to condense the $18 \mathrm{~T}$-atom channel to 14 T-atom channel and transform to another crystall ine phase $\mathrm{AlPO}_{4}-8$ at temperatures higher than ca. $100^{\circ} \mathrm{C} .38$

\section{Conclusions}

By using $n$-alkylamines of four to eight carbon chain length as templates, a novel al uminophosphate (AIPOntu) of lamellar structure was synthesized under hydrothermal condition. The as-synthesized AIPO-ntu compounds have chemical compositions led to formula AlPO $3(\mathrm{OH})_{2}\left[\mathrm{NH}_{2}\left(\mathrm{CH}_{2}\right)_{n} \mathrm{CH}_{3}\right]$, where $\mathrm{n}=3$, 5, or 7 for butyl-, hexyl-, and octylamines, respectively. Solid-state ${ }^{27} \mathrm{Al}$ and ${ }^{31} \mathrm{P}$ NMR spectra demonstrate that both $\mathrm{Al}$ and $\mathrm{P}$ atoms are tetrahedrally coordinated and in single coordination environments. These results accompanied with those from X-ray diffraction, ion-exchange properties and FT-IR spectra strongly support that the sheet structure of AIPO-ntu is similar to that of kanemite. The $\mathrm{AlO}_{4}$ and $\mathrm{PO}_{4}$ tetrahedra lie alternatively and form sheets of interlocking six-T-member rings. Each tetra-

(38) Sorby, K.; Szostak, R.; Ulan, J . G.; Gronsky, R. Catal. Lett. 1990, 6, 209. hedral $\mathrm{TO}_{4}$ group $(\mathrm{T}=\mathrm{Al}$ or $\mathrm{P}$ ) has three oxygen atoms bonded to three different $T$ atoms, while the fourth unshared oxygen atom on $\mathrm{AlO}_{4}$ bears a proton and that on $\mathrm{PO}_{4}$ bears an alkylammonium ion. The al kylammonium ions are exchangeable with alkali ions, but the protons on $\mathrm{Al}-\mathrm{O}$ terminals are not. The six-T-member rings in aluminophosphate layer shall arrange in boat form in order to explain the thin-sheet structure observed and the bilayer structure formed by the interlayer alkylammonium ions. The $\mathrm{Na}^{+}$-exchanged AIPOntu has a chemical formula NaHAIPO${ }_{5} \cdot \mathrm{XH}_{2} \mathrm{O}$, which is isoelectronic to naturally occurring silicate mineral, kanemite with a formula $\mathrm{NaHSi}_{2} \mathrm{O}_{5} \cdot 3 \mathrm{H}_{2} \mathrm{O}$. Moreover, the AIPO-ntu layers act similarly as the single-layered silicate in condensation and transforming to porous network under the influence of the polar headgroup of exchanged surfactant cations. Nevertheless, the resultant porous structure has no long-range arrangement of hexagonal pores and is thermally unstable.

Acknowledgment. Financial support from the $\mathrm{Na}$ tional Science Council in Taiwan, Republic of China, is gratefully acknowledged.

CM9700357 